\title{
Comparative Study of Non-descent Vaginal Hysterectomy with Total Abdominal Hysterectomy
}

\section{Rubina Shrestha,' Subha Shrestha,' Satindar Ray'}

'Department of Obstetrics and Gynaecology, College of Medical Sciences-Teaching Hospital, Bhratpur, Chitwan, Nepal

\section{ABSTRACT}

\section{Introduction}

Hysterectomy is the most common operation performed by gynecologist worldwide. In the present era emphasis is given on minimal invasive surgery so Non-Descent Vaginal Hysterectomy (NDVH) has gained more interest over Total Abdominal Hysterectomy (TAH). NDVH has several benefits over TAH in terms of blood loss, operating time, post-operative complications, recovery and hospital stays.

The objective of the study was to compare the clinical outcome of NDVH over TAH with respect to operating time, blood loss, hospital stays, intraoperative and early postoperative complication and to find out the most efficient route for hysterectomy.

\section{Methods}

The study was conducted at College of Medical Science-Teaching Hospital, Bharatpur, Chitwan, Nepal between May 2017- May 2020. Fifty cases each of NDVH and TAH group fulfilling the selection criteria were included in the study. Outcome was measured on the basis of operating time, blood loss, hospital stay and intra and post-operative complications.

\section{Results}

Baseline characteristics were similar between both the groups. The most common indication for hysterectomy in both the group was fibroid uterus. There was no intra-operative complication in NDVH group but in TAH group bowel injury was encountered in 3 cases. The operating time, blood loss, hospital stay and post-operative complications were less in NDVH as compare to TAH

\section{Conclusions}

NDVH is the better choice of surgery than TAH for the non-prolapsed uterus, size less than 12 weeks with benign pathology.

Keywords: non-descent vaginal hysterectomy; total abdominal hysterectomy.

Correspondence: Dr. Rubina Shrestha, College of Medical Sciences- teaching Hospital, Bharatpur-10, Chitwan, Nepal. Email: rubinashrestha2@gmail.com, Phone: + 977-9849982644. 


\section{INTRODUCTION}

Hysterectomy is one of the most common surgeries performed by gynecologist worldwide next to cesarean section. ${ }^{1,2}$ Abdominal route is preferred over vaginal route for non-prolapsed uterus even though multiple studies stating that the vaginal route is preferred to abdominal route. ${ }^{3}$ The ease and convenience offered by a large abdominal incision and better operative field vision have led to preference of abdominal route over vaginal route. But, now as emphasis is on minimal invasive surgery so vaginal and laparoscopic route has gained interest even for non- prolapsed uterus. ${ }^{4,5} \mathrm{NDVH}$ is less invasive, scar less operation and cost effective for patient but it has its own limitation like difficult to approach through narrow vagina, adnexal pathology and in scarred uterus. ${ }^{6}$ However, proper selection of the patient is a key factor to determine the success of NDVH. So, this study is done to know the clinical outcome between NDVH and TAH.

\section{METHODS}

This study was retrospective study and was carried out to compare vaginal hysterectomy and abdominal hysterectomy in non-descent uterus. The main objective of this study was to compare the clinical outcome between NDVH and TAH with respect to operating time, blood loss, intra-operative and early post-operative complication and find out which is the most efficient route for hysterectomy in women with mobile non-prolapsed uterus of 12 weeks or less. The study was carried out at College of Medical Sciences, Bharatpur, Nepal, a tertiary care institute. The ethical clearance was taken from College of Medical Sciences and Teaching Hospital - Institutional Review Committee (COMSTH-IRC) with the reference numberCOMSTH-IRC/2020-10024. Total 100 cases that underwent hysterectomy in between January
2018 to December 2019 who met the inclusion criteria were randomly selected out of which 50 cases underwent TAH and 50 cases underwent NDVH. Patient who underwent hysterectomy for benign lesion of uterus, completed family, gynecologic symptoms that justified hysterectomy and uterus size less than 12 weeks of gravid uterus were included in the study. Patients with uterine size more than 12 weeks, restricted mobility, pelvic organ prolapsed, and patient with complex adnexal mass were excluded from the study.

The patients detail history, clinical evaluation, investigation and pre-anesthetic check-up details were taken from history sheet. The patients detail operation notes were taken from case sheet and operative notes. Operating time for NDVH was calculated after incision of cervicovaginal junction to closure of vault. Operating time for TAH was calculated from incision of skin to closure of skin incision. Data regarding age, parity, uterine size, indication of operation, estimated blood loss during intra-operative period was calculated using Gauze Visual Analogue, ${ }^{7}$ any intra-operative complication, length of operation, time taken by patient to ambulate voluntarily, any complication, blood transfusion and duration of hospital stay was also recorded.

Post-operatively all the patients were prescribed an identical regime of analgesia and prophylactic antibiotics for 7 days. Febrile morbidity and any other post-operative complications such as haemorrhage, urinary tract infection, wound infection, vault infection, secondary suturing and any other complications were recorded. Statistical analysis was done by descriptive and inferential statistics using student unpaired ' $\mathrm{t}$ ' test, Chi square test. Data entry was done in excel and data analysis was done using software, SPSS. Data were analysed as graphs and charts. 


\section{RESULTS}

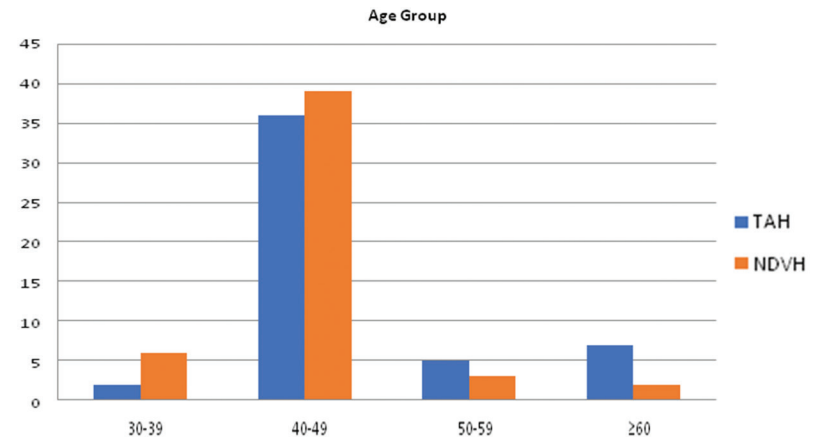

Fig 1: Distribution of cases according to age group.

Majority of the patients were in age group 40-49 years i.e $72 \%$ in TAH group and $78 \%$ in NDVH group. Most of the cases were multiparae with no significant differences in two groups.

Table 1. Distribution of cases according to uterine size.

\begin{tabular}{|c|c|c|l|}
\hline $\begin{array}{c}\text { Size of } \\
\text { the uterus } \\
\text { (in weeks) }\end{array}$ & TAH & NDVH & $\begin{array}{c}\text { Total no of } \\
\text { cases }\end{array}$ \\
\hline 6 & $6(12 \%)$ & $8(16 \%)$ & $14(14 \%)$ \\
\hline 8 & $14(28 \%)$ & $16(32 \%)$ & $30(30 \%)$ \\
\hline 10 & $19(38 \%)$ & $14(28 \%)$ & $33(33 \%)$ \\
\hline 12 & $11(11 \%)$ & $12(24 \%)$ & $23(23 \%)$ \\
\hline Total & $50(100 \%)$ & $50(100 \%)$ & $100(100 \%)$ \\
\hline
\end{tabular}

Most common indication for hysterectomy in both the groups was fibroid uterus, $52 \%$ in TAH group and $35 \%$ in NDVH group. Second most common indication was AUB followed by adenomyosis.

Table 2. Distribution of patients according to indication of surgery.

\begin{tabular}{|l|l|l|}
\hline \multicolumn{1}{|c|}{$\begin{array}{c}\text { Indication of } \\
\text { surgery }\end{array}$} & $\begin{array}{c}\text { No of Cases } \\
\text { in TAH(\%) }\end{array}$ & $\begin{array}{c}\text { No of cases } \\
\text { in NDVH(\%) }\end{array}$ \\
\hline Fibroid & $26(52 \%)$ & $35(70 \%)$ \\
\hline AUB & $9(18 \%)$ & $7(14 \%)$ \\
\hline Adenomyosis & $7(14 \%)$ & $7(14 \%)$ \\
\hline Endometriosis & $4(8 \%)$ & $0(0 \%)$ \\
\hline Chronic cervicitis & $0(0 \%)$ & $1(2 \%)$ \\
\hline $\begin{array}{l}\text { Benign ovarian } \\
\text { tumour }\end{array}$ & $4(8 \%)$ & $0(0 \%)$ \\
\hline Total & $50(100 \%)$ & $50(100 \%)$ \\
\hline
\end{tabular}

Entire uterus was removed in 44 cases of NDVH without any difficulty, $5(10 \%)$ patients required bissection of uterus and $1(2 \%)$ cases required myomectomy for easy removal of uterus during NDVH.

Table 3. Comparison of operative time (mins) in both groups.

\begin{tabular}{|l|l|l|l|l|}
\hline $\begin{array}{l}\text { Operative } \\
\text { time (min) }\end{array}$ & Mean & SD & t-value & p-value \\
\cline { 1 - 3 } TAH & 93 & 27.27 & 5.01 & $\begin{array}{c}<0.0001 \\
\text { Highly } \\
\text { significant }\end{array}$ \\
\cline { 1 - 3 } NDVH & 69.28 & 19.4 & &
\end{tabular}

Table 4. Comparison of intra-operative blood loss in both groups.

\begin{tabular}{|l|l|l|l|c|}
\hline $\begin{array}{c}\text { Blood } \\
\text { loss(ml) }\end{array}$ & Mean & \multicolumn{1}{|c|}{ SD } & t-test & p value \\
\cline { 1 - 3 } TAH & 199.5 & 77.83 & 3.98 & $\begin{array}{c}0.0001 \\
\text { Highly } \\
\text { significant }\end{array}$ \\
\hline NDVH & 123.9 & 109.12 & &
\end{tabular}

In our study $12 \%$ cases in TAH required blood transfusion and $6 \%$ cases of NDVH required blood transfusion post-operatively. There was no intra-operative complication in NDVH group whereas in TAH group 3 patients out of 50 had bowel injury due to dense adhesion during intra-operative period.

In this study majority of cases $82 \%$ had ambulated before 24 hours but in NDVH only $52 \%$ cases had ambulated before 24 hours and $24 \%$ had ambulated after 24 hours, $p$ value is 0.0004 which was statistically significant.

In this study post operative complications was seen in $26 \%$ of patient in TAH group and in $14 \%$ in NDVH group. Urinary tract infection (UTI) was most commonly seen in NDVH group than $\mathrm{TAH}$. Other complications were higher on TAH than NDVH group. 


\begin{tabular}{|l|l|l|l|l|}
\hline \multicolumn{6}{|l|}{ Table 5. Comparison of post-operative complications in both groups } \\
\cline { 1 - 3 } Post operative complication & No of cases in TAH(\%) & NO of cases in NDVH(\%) & Total no of cases (\%) & P Value \\
\hline None & $37(74 \%)$ & $43(86 \%)$ & $80(80 \%)$ & \\
\hline Pyrexia & $3(6 \%)$ & $2(4 \%)$ & $5(5 \%)$ & \\
\hline Paralytic lileus & 0 & $0(0 \%)$ & $0(0 \%)$ & \multirow{2}{*}{0.008} \\
\hline UTI & $1(2 \%)$ & $5(10 \%)$ & $6(6 \%)$ & \multirow{2}{*}{ Significant } \\
\hline Wound Infection & $4(8 \%)$ & $0(0 \%)$ & $4(4 \%)$ & $1(1 \%)$ \\
\hline Resuturing & $1(2 \%)$ & $0(0 \%)$ & $4(4 \%)$ & \\
\hline Vault infection & $4(4 \%)$ & $0(0 \%$ & & \\
\hline
\end{tabular}

Table 6. Comparison total duration of postoperative hospital stay in both groups.

\begin{tabular}{|l|l|l|l|c|}
\hline $\begin{array}{c}\text { Hospital stay } \\
\text { (days) }\end{array}$ & Mean & SD & t-test & p value \\
\hline TAH & 8.28 & 3.77 & 7.9 & $\begin{array}{c}<0.0001 \\
\text { Highly } \\
\text { significant }\end{array}$ \\
\hline NDVH & 4.06 & 0.23 & 7.9 \\
\hline
\end{tabular}

\section{DISCUSSION}

Hysterectomy is the one of the major gynaecological surgeries performed worldwide. Around $70-80 \%$ of hysterectomies done for benign condition are through abdominal route, despite the evidence has showed the abdominal route have higher incidence of complication, longer length of hospital stay and greater hospital charges as compared to vaginal route. ${ }^{8}$ Vaginal hysterectomy were usually performed for prolapsed uterus in past, but with introduction of hemisection, morcellation, increase enthusiasm and technical skills among gynaecologist, vaginal hysterectomy has also become a choice of surgery for benign non-prolapsed cases. The main support of uterus, the uterosacral and cardinal ligaments situated in close proximity to vaginal vault, can be easily divided to produce uterine descent. ${ }^{9}$ In this era of minimal invasive surgery, patients are desperate to avoid large abdominal incision which has lead increase the interest and importance of NDVH as the scar less hysterectomy for benign condition. The advantages of NDVH over TAH have prompted numerous investigations to recommend NDVH for women whose conditions permit the approach. This study of comparison between $\mathrm{NDVH}$ and TAH is also done with same interest.

In the present study, most of the patent were in age group 40-49 years of age and were multiparae, which were compatible to study done by Abrol $S$ et al. ${ }^{10}$ In present study most common indications for hysterectomy in both the group was fibroid uterus, followed by AUB and adenomyosis which was similar to study done by Mehta K. et al. ${ }^{11}$ In present study mean uterine size in TAH group was 9.4 weeks and in NDVH group was 8.82 weeks. In a study done by Miskry $\mathrm{T}$ et al. the mean uterine size in TAH group was 6.9 weeks which was smaller than the NDVH group 7.8 weeks. ${ }^{12}$ In present study 3 patients has bowel injury due to dense adhesion during intra-operative period in $\mathrm{TAH}$ group whereas no intra-operative complication was noted in NDVH group. In a study conducted by Somjita $\mathrm{C}$ et al. equal bladder injury was reported in both the groups and there was no ureteric and bladder injury. ${ }^{13}$

In present study mean blood loss in $\mathrm{TAH}$ group was $199.5 \mathrm{ml}$ which was more than the NDVH group which was $123.9 \mathrm{ml}$. Even in the $\mathrm{NDVH}$ which required debulking for easy removal of uterus, mean blood was $147.5 \mathrm{ml}$ which is still 
less than in TAH group. This is comparable to study done by Modi K et al. ${ }^{14}$

The mean operation time in our study was more in TAH group compared to NDVH group (93min vs $69.28 \mathrm{~min}$ ) and this was comparable to studies done by Benassi et al, Hwang et al. ${ }^{15,16}$ Even in NDVH group which required debulking the mean operating time 84.5 min was less than in TAH.

In our study during post-operative period UTI was encountered in 10\% in NDVH group which was more than in TAH group which was $4 \%$. The incidence of pyrexia, wound infection, vault infection and secondary suturing was high in TAH as compared to NDVH which is similar to study done by Mehta Ket al, Goswami et al ,Chen $B$ et al and ${ }^{11,17,18}$ In this study resuturing was needed in $2 \%$ cases of TAH which was similar to study done by Bharatnur S. ${ }^{19}$ Mc Cracken et al. in their study also concluded that intra-operative and post-operative morbidity were lesser in vaginal hysterectomy compared to abdominal hysterectomy and that vaginal hysterectomy is an acceptable method of hysterectomy despite previous belief that it is contraindication in certain conditions. ${ }^{20}$

\section{REFERENCES}

1. Bernstein SJ, McGlyn EA, Siu AL. The appropriateness of hysterectomy. A comparison of care in seven health plans. Health maintenance organization quality of care consortium. JAMA. 1993;269-2398.

2. Grave EJ, Gillum BS. 1994 Summary. National hospital discharge survey. Advance data from vital and health statistics No 278. National Center for Health Statistics, Hyattsville, Maryland 1996
In the present study most of the cases in NDVH, $82 \%$ were ambulatory in $<24$ hours while in TAH group most cases 52\% were ambulatory in $>24$ hours. It is comparable to study done by Mehta $\mathrm{K}$ et al. where $66 \%$ were ambulatory in $<24 \mathrm{hrs}$ in NDVH group and most cases about $50 \%$ were ambulatory after 48 hours in TAH group. ${ }^{11}$ In our study mean duration of hospital stay in $\mathrm{NDVH}$ was 4.06 days while in TAH group mean duration of hospital stay was 8.28 days, which is similar to study done by Chuvan et al and Balakrishnan D et al. ${ }^{21,22}$ A Cochrane review of 34 randomized trials of vaginal, abdominal and laparoscopic hysterectomy, in which 4,495 patient were included concluded that vaginal hysterectomy has the best outcomes among these routes.

\section{CONCLUSIONS}

From the present study it is concluded that NDVH has less post operative morbidity, less operating time, blood loss, shorter length of hospital stay and early post-operative mobilization as compared to TAH. So, with proper selection of cases and trained gynecologist NDVH is better choice than TAH.

3. ACOG Committee Opinion. Number 311, April 2005. Appropriate use of laparoscopically assisted vaginal hysterectomy. Obstet Gynecol. 2005;105: 929-30.

4. Richardson RE, Bournas N, Magos AL. Is laparoscopic hysterectomy a waste of time? Lancet. 1995;345:36-41

5. Balakrishnan D, Dibyajyoti G. A COmparision between Non- descent vaginal hysterectomy and total abdominal hysterectomy. Journal of clinical and Diagnostic Research, 2016 Jan, Vol-10(1):QC11-QC14. 
6. Durga BC, Sharma A, Mahaseth B, Sharma N. A Comparative evaluation of Non-descent vaginal hysterectomy versus total Abdominal hysterectomy: A hospital based case control study. Journal of Nepalgunj Medical College. 2019 Aug 22;17(1):20-2.

7. Ali Algadiem E, Aleisa AA, Alsubaie $\mathrm{HI}$ et al. Blood loss estimation using gauze piece visual analogue. Trauma Mon.2016;21:e3413

8. Bhandra B, Choudhury Ap, Nagpur AJN. Non descent vaginal hysterectomy: Personal experience in 148 cases J med SCI. 2011;4:23-7

9. Rupali D, Shivani A, BHarati MM et al. Non- descent vaginal hysterectomy An experience. J Obstet Gynaencol. 2004;56:376-8

10. Abrol S, Rashid S, Jabeen F, Kaul S. Comparative analysis of nondescent vaginal hysterectomy versus total abdominal hysterectomy in benign uterine disorders. Int J Reprod Contracept Obstet Gynecol. 2017;6(3):846-9.

11. Mehta K, Prakash O, Fatehpuriya DS, Verma L. Comparative study of abdominal hysterectomy and vaginal hysterectomy in non descent cases - a prospective study. Int J Reprod Contracept Obstet Gynaecol. 2017 Apr;6(4):1265-70.

12. Miskry T, Magos A. Randomized, prospective, double-blind comparison of abdominal and vaginal hysterectomy in women without uterovaginal prolapse. Acta obstetricia et gynecologica Scandinavica. 2003 Jan
1;82(4):351-8.

13. Chakraborty S, Goswami S, Mukherjee P, Sau M. Hysterectomy..... Which Route?. The Journal of Obstetrics and Gynecology of India. 2011 Oct 1;61(5):554-7.

14. Modi K, Patel S, Gupta S, Barnwal R, Desai A et al. Non- Descent Vaginal Hysterectomy A Comparative Analysis. IJSR. 2014:3(11);414-6

15. Benassi L, Rossi T, Kaihura CT, Ricci L, Bedocchi L, Galanti B, Vadora E. Abdominal or vaginal hysterectomy for enlarged uteri: a randomized clinical trial. American journal of obstetrics and gynecology. 2002 Dec 1;187(6):1561-5.

16. Hwang JL, Seow KM, Tsai YL, Huang LW, Hsieh BC, Lee C. Comparative study of vaginal, laparoscopically assisted vaginal and abdominal hysterectomies for uterine myoma larger than $6 \mathrm{~cm}$ in diameter or uterus weighing at least 450 g: a prospective randomized study. Acta obstetricia et gynecologica Scandinavica. 2002 Jan 1;81(12):1132-8.

17. Goswami D et al. Non-descent vaginal hysterectomy versus total abdominal hysterectomy in fibroid uterus: a comparative study in tettiary care hospital in Uttarakhand, India. Int J Reprod ContraceptObstetGynaecol.2016 Aug;5(8):2718-22

18. Chen B, RenDP, Li JX, Li CD. Comparison of vaginal and abdominal Hysterectomy: a prospective non-randomized trial. Pak J Med Sci.2014;30(4):875-9

19. Bharatnur S. Comparative study of abdominal hysterectomy versus vaginal hysterectomy in non- 
Shrestha et al. Comparative Study of Non-descent Vaginal Hysterectomy with Total...

descent cases. Internet J Gynecology Obstetrics.2010;12(2)

20. Mc Craken G, Hunter D, Morgan D, Price JH. Comparison of laparoscopic assisted vaginal hysterectomy, total abdominal hysterectomy, and vaginal hysterectomy. Ulster Med Journal. 2006;75(1):54-58.

21. Balakrishnan D, Dibyajyoti G. A comparison between non-descent vaginal hysterectomy and total abdominal hysterectomy. Journal of clinical and diagnostic research: JCDR. 2016 Jan;10(1):QC11.

22. Chavhan RP, Aroma G, Pajai S. Comparative study between vaginal and abdominal hysterectomy in non-descent cases. Int J Sci Rep. 2016 Mar 19;2(3):4852.

Citation: Shrestha R, Shrestha S, Ray S. Comparative Study of Non-descent Vaginal Hysterectomy with Total Abdominal Hysterectomy. JCMS Nepal. 2021; 17(3); 220-26.

226

JCMS | Vol-17 | No 3 | Jul-Sept. 2021 